\title{
Photosynthetic Characteristics of Apple Spur Leaves after Summer Pruning to Improve Exposure to Light
}

\author{
Kuo-Tan Li ${ }^{1}$ and Alan N. Lakso \\ Department of Horticultural Sciences, New York State Agricultural Experiment \\ Station, Cornell University, Geneva, NY 14456
}

Addition index words. Malus $\times$ domestica, canopy light interception, photosynthesis, chlorophyll fluorescence, specific leaf weight

\begin{abstract}
Summer pruning increases canopy light penetration and re-exposes spur leaves of the interior canopy of apple trees (Malus $\times$ domestica Borkh.). However, we hypothesized that leaf photosynthetic ability is determined by the pre-pruning light environment, and the re-exposure intensity after summer pruning is incapable of restoring the photosynthesis efficiency of shaded leaves. To test this hypothesis, a commercial-type thinning-cuts pruning was applied to mature central leader 'Empire'/M.26 apple trees. Changes in light availability, leaf net photosynthesis (Pn), photosystem II efficiency, and specific leaf weight (SLW) were recorded periodically before and after pruning. Leaf photosynthesis declined slightly through the growing season and was well correlated with pre-pruning light availability until late September. Although Pn decreased more substantially late in the season on exterior leaves than on interior leaves, Pn of leaves in the inner and middle canopies was lower than exterior leaves until late October. Maximum efficiency of photosystem II of dark-adapted leaves, measured by chlorophyll fluorescence $(\mathrm{Fv} / \mathrm{Fm})$, was not related to prior exposure or re-exposure. Specific leaf weight was well correlated with pre-pruning light availability and with leaf Pn in August but not in October. Results suggested that commercial summer pruning significantly increases light environments in the inner and middle canopies. However, light availability at interior and middle canopy sites was still much lower than exterior canopy and, consequently, leaf photosynthetic ability did not increase after summer pruning.
\end{abstract}

Apple dry matter and yield are driven by total light interception (Jackson, 1980; Lakso, 1994; Palmer, 1989); however, yield variations are more closely correlated with light interception by the spur canopy (Wünsche et al., 1996). Therefore, many tree training and pruning techniques are designed to obtain adequate total light interception as well as maintain a good light penetration into the canopy (Jackson, 1980; Lakso and Robinson, 1997; Palmer, 1989; Robinson, 1997) to maximize the light interception to spur leaves.

Summer pruning, a traditional orchard practice to enhance fruit color and control tree size, is one of the most direct and effective approaches to improve light penetration into the canopy later in the season (Marini and Barden, 1987; Saure, 1987). However, summer pruning often results in smaller fruit size (Katzler and Wurm, 1998; Marini and Barden, 1982c; Myers and Ferree, 1983b), indicating that the practice impairs the ability of the tree to support final fruit growth. Palmer et al. (1992) found that removing $10 \%$ to $30 \%$ of the leaf area by summer pruning reduced total light interception by $6 \%$ to $14 \%$. Although the style of summer pruning may vary and affect light interception more or less, this raises questions

\footnotetext{
Received for publication 5 Nov. 2002. Accepted for publication 27 May 2003. We thank Thomas Björkman and Lailiang Cheng for critical reviews of this manuscript. Mention of a trademark does not imply endorsement of the product named, or criticism of similar products not named.

${ }^{1}$ To whom reprint requests should be addressed; e-mailKL46@cornell.edu.
}

about the effects of summer pruning on tree productivity. In addition to possible reductions in light interception, the redistribution of light to previously shaded interior leaves after summer pruning may affect the efficiency of light conversion to photoassimilates as well.

The negative effects of natural and artificial shading on canopy and leaf photosynthesis efficiency have been investigated in various apple cultivars and orchard systems (Mika and Antoszewski, 1972; Porpiglia and Barden, 1980; Tustin et al., 1992). Although leaves of many other species have shown the capability to adapt to different light intensities even after leaf expansion has ceased (Boardman, 1977), removing the well-exposed apple leaves on the outer canopy has not shown a clear effect of re-exposure on photosynthesis of the previously shaded leaves. Some earlier studies on young container-grown and mature apple trees suggested that summer pruning increased net photosynthesis $(\mathrm{Pn})$ of shoot leaves close to the heading cut sites (Ferree et al., 1984; Marini and Barden, 1982b; Myers andFerree, 1983a; Taylor and Ferree, 1981). Recently, Mierowska et al. (2002) also reported that Pn rates of spur leaves increased significantly after exposure to full sun light by summer pruning. On the other hand, Porpiglia and Barden's (1981) research indicated noeffect of re-exposure on photosynthetic performance of spur leaves. Lakso et al. (1989) found reductions in the photosynthesis rates of interior spur leaves after summer pruning, and the severity was correlated to the pre-pruning light exposure. No obvious recovery occurs after re-exposure for 2 weeks.
The major objective of this study was to evaluate the effects of summer pruning on the photosynthesis capacity of leaves of varying locations in mature 'Empire' apple trees in the field with a commercial pruning approach and intensity. The approach was to correlate lightsaturated leaf Pn at different canopy positions to light availability before and after summer pruning with leaf gas exchange, chlorophyll fluorescence, and specific leaf weight (SLW).

\section{Materials and Methods}

Plantmaterials. Thirteen-year-old 'Empire'/ M.26 central leader apple trees were selected in north-south rows at the New York State Agricultural Experiment Station in Geneva, N.Y. Trees were an average of $3 \mathrm{~m}$ wide and $4.5 \mathrm{~m}$ tall with spacing of $3 \mathrm{~m}$ within rows and 4.5 $\mathrm{m}$ between rows, growing in a deep loam soil and well managed with commercial fertilization and pest control. To create a diversity of light environments, variable pruning treatments were applied in Summer 1996 to open the canopies of some trees while the others remained dense canopies.

Summerpruning treatment. On 7 Aug. 1997, when growth of most of the extension shoots was terminated, all trees in the two rows received a moderate pruning treatment to open the canopy and allow interior leaves to receive more sunlight. Thinning cuts were used to remove entire extension shoots from the point of origin, or back to the first fruiting spur on the 1-year-old wood. About $30 \%$ to $40 \%$ of the extension shoots were thinned out from the canopy after the pruning treatment. No remarkable reduction in canopy light interception was observed.

Light environment measurement. The term light will refer to photosynthetic photon flux $(P P F)$ as measured with quantum sensors (LI-190SA; LI-COR, Lincoln, Nebr.). On 19 June $1997, \approx 1$ month after bloom, 14 canopy locations representing a range of light exposures were visually identified in the canopies of four test trees. Light availability for each selected location was estimated with fisheye photography and image analysis system at 2- to 3-week intervals from mid-June until the pruning was done in early August. Briefly, black-and-white fisheye photographs were taken under overcast conditions with a fisheye lens $\left(180^{\circ}, 8-\mathrm{mm}\right.$ auxiliary lens, Samigon, Tokyo) mounted on a 50-mm lens (Nikkor 50-mm 1:2 lens, Nikon Co., Tokyo) of a camera. The camera was leveled, pointed directly upward and oriented with a mark to true north. Pictures were then digitized with an image analysis system (FD 5000; Gould, San Jose, Calif.) that estimated both direct and diffuse light transmission by custom software. The percentage of the available diffuse light for a given image was then calculated by the percentage of pixels with visible sky over the entire image with corrections for lens distortion and sky luminosity by the Standard Overcast Sky equation (Monteith and Unsworth, 1990). Direct light availability was estimated by determining the percentage of sky pixels in the calculated solar track using a $5^{\circ}$ width and appropriate corrections for lens distortion. Overall light availability for the given location was then 
estimated from measured values of diffuse and direct light from the Climatological Reference Station at the New YorkAgricultural Experiment Station, Geneva, N.Y.

Leaf performance measurements. Lightsaturated leaf photosynthesis was measured in full sunlight a day before and a day after pruning treatment in August, and then bi-weekly after pruning until mid-October. Two healthy leaves from spurs at each of the 14 selected locations were labeled in early June and used for the experiment over the season. Leaf gas exchange was measured with a portable opensystem gas exchange analyzer (CIRAS-1; PP Systems, Hitchin, Herts, U.K.) under sunny conditions between 0930 and 1300 HR solar time. Before summer pruning, branches were temporarily repositioned to allow for at least 1 $\mathrm{h}$ at full sunlight on interior leaves before Pn measurement.

On the same leaves used for gas exchange, PSII chlorophyll efficiency was measured by recording dark-adapted chlorophyll fluorescence emission with a pulse-modulated fluorometer (OS-100; Opti-Science, Tyngsboro, Mass.). Prior to the measurement, leaves were darkadapted for at least $15 \mathrm{~min}$ with dark-adapting leaf clips to ensure all the PSII reaction centers in the area being covered by the clips were in an active, "open" state. Fluorescence was excited by low intensity $\left(<1 \mu \mathrm{mol} \cdot \mathrm{m}^{-2} \cdot \mathrm{s}^{-1}\right)$ modulated $655-\mathrm{nm}$ light. Fluorescence emission was detected in the 710- to 760-nm ranges. After the minimal fluorescence $\left(F_{0}\right)$ was recorded, the photosystem was saturated by a high intensity light pulse of 350 to $700 \mathrm{~nm}$ for $1 \mathrm{~s}$ to induce the maximum fluorescence $\left(\mathrm{F}_{\mathrm{m}}\right)$. Variable fluorescence $\left(\mathrm{F}_{\mathrm{v}}\right)$ was calculated from $\left(\mathrm{F}_{\mathrm{m}}-\mathrm{F}_{0}\right)$ and the potential yield of the photochemical reaction, or the photochemical efficiency of PSII, was obtained from $\mathrm{F}_{\mathrm{v}} / \mathrm{F}_{\mathrm{m}}$.

Three leaves close to the monitored leaves from each canopy location were sampled on 12 Aug. and 16 Oct. for SLW measurement. Leaf area was recorded with an image analysis system (AgVision; Decagon Devices, Pullman, Wash.). Dry weight was determined after oven-drying.

\section{Results and Discussion}

Light environment. Measurements with fisheye photography indicated that apple canopies were mostly closed by mid-June, as interior light availability was quite stable from then until early August (data not shown). The tree canopy was fully developed in early August before the pruning treatment. Due to the natural and imposed shading effect from varying canopies, light availability before summer pruning varied from $2 \%$ to $80 \%$ (Fig. 1). Estimated cumulative incident solar radiation was $1340 \mathrm{MJ} \cdot \mathrm{m}^{-2}$ from 5 June to 7 Aug. 1997.

The commercial-style thinning-cuts summer pruning enhanced light environment for inner and middle canopies, although the light that reached the interior canopy was still low even after the pruning (Fig. 1). After summer pruning, changing branch angle due to increased fruit weight until harvest slightly enhanced the canopy light environment again.

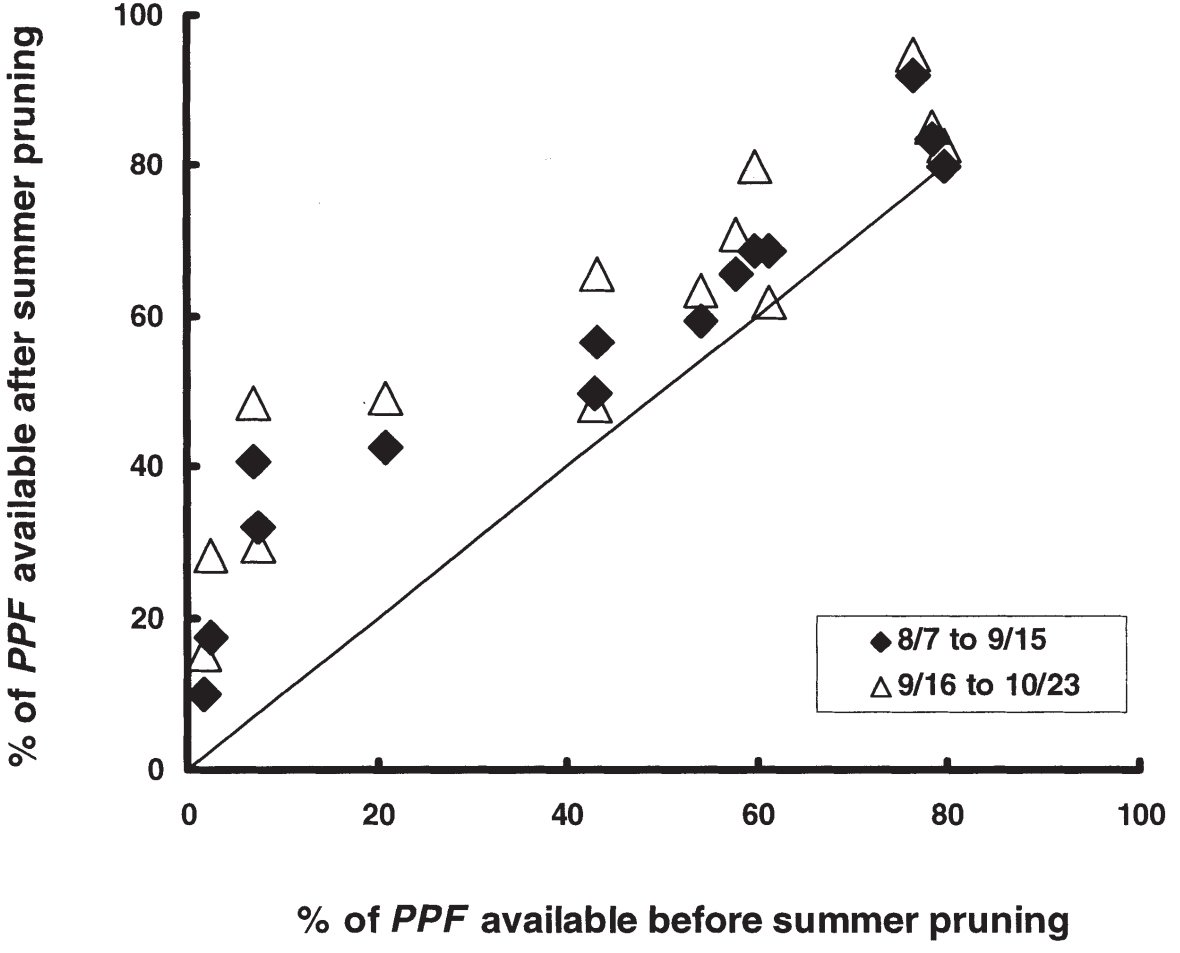

Fig. 1. Light availability at 14 canopy positions before and after summer pruning 14-year-old modified central leader 'Empire'/M.26 apple trees. Trees were summer pruned on 7 Aug. Estimated cumulative solar radiation from 5 June to 7 Aug. was $1340 \mathrm{MJ} \cdot \mathrm{m}^{-2}, 586 \mathrm{MJ} \cdot \mathrm{m}^{-2}$ for 8 Aug. to 15 Sept., and 415 $\mathrm{MJ} \cdot \mathrm{m}^{-2}$ for 16 Sept. to 23 Oct.

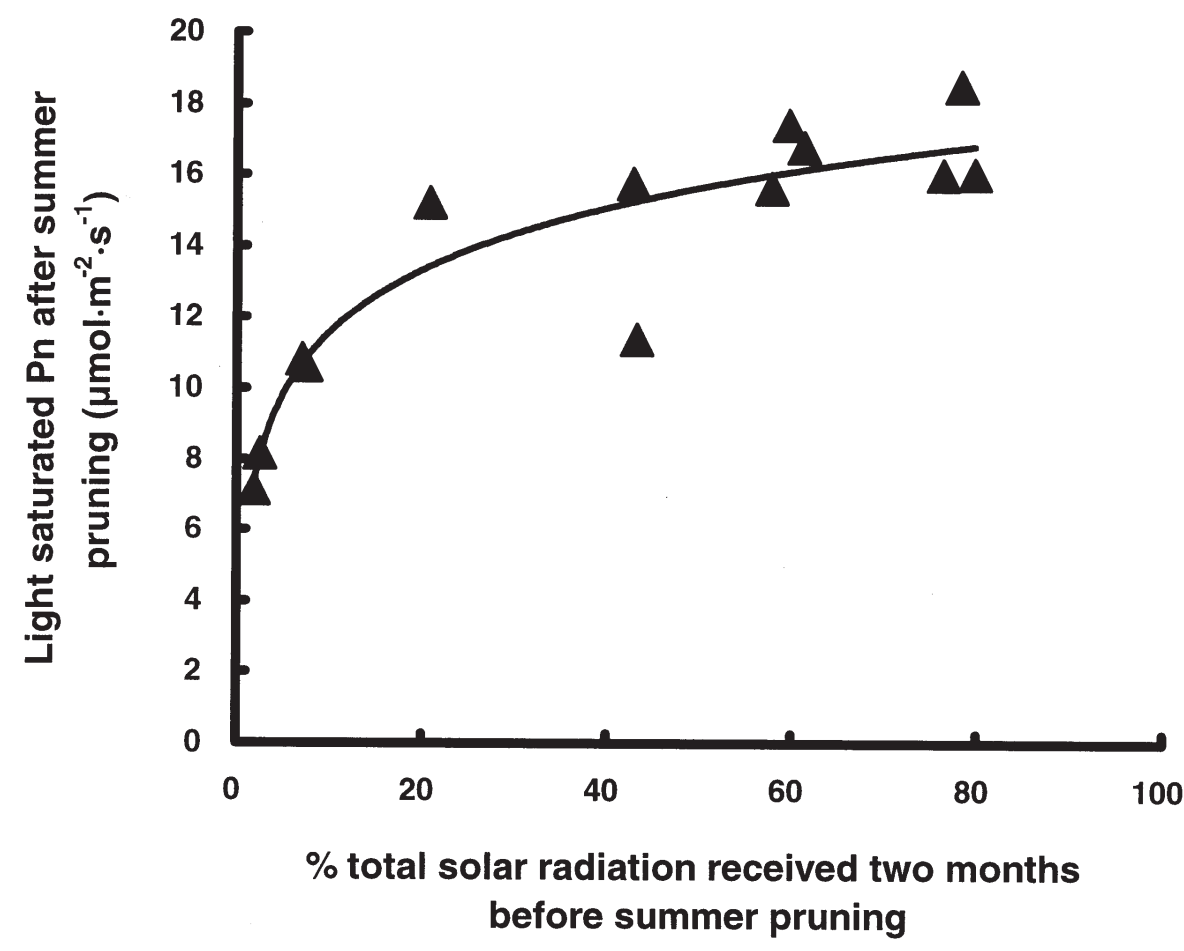

Fig. 2. Light-saturated net photosynthesis of spur leaves from different canopy positions in 14-year-old modified central leader 'Empire'/M.26 apple trees at $5 \mathrm{~d}$ after summer pruning as a function of prior light environment. Trees were summer pruned on 7 Aug. Cumulative solar radiation from 5 June to 7 Aug. 1997 was $1340 \mathrm{MJ} \cdot \mathrm{m}^{-2}$. The regression model is $\mathrm{y}=2.5 \mathrm{Ln}(\mathrm{x})-8.7, r^{2}=0.8$.

However, the cropping and harvest effect was much smaller than the summer pruning effect. This was also observed by Marini and Barden (1982a). Compared to the results on 'Gala' trees from Morgan et al. (1984), our pruning treatment improved canopy light transmission to a greater extent, but slightly less than results from Mika (1986). The differences are possibly due to the combination of pruning style and intensity, canopy architecture before summer 


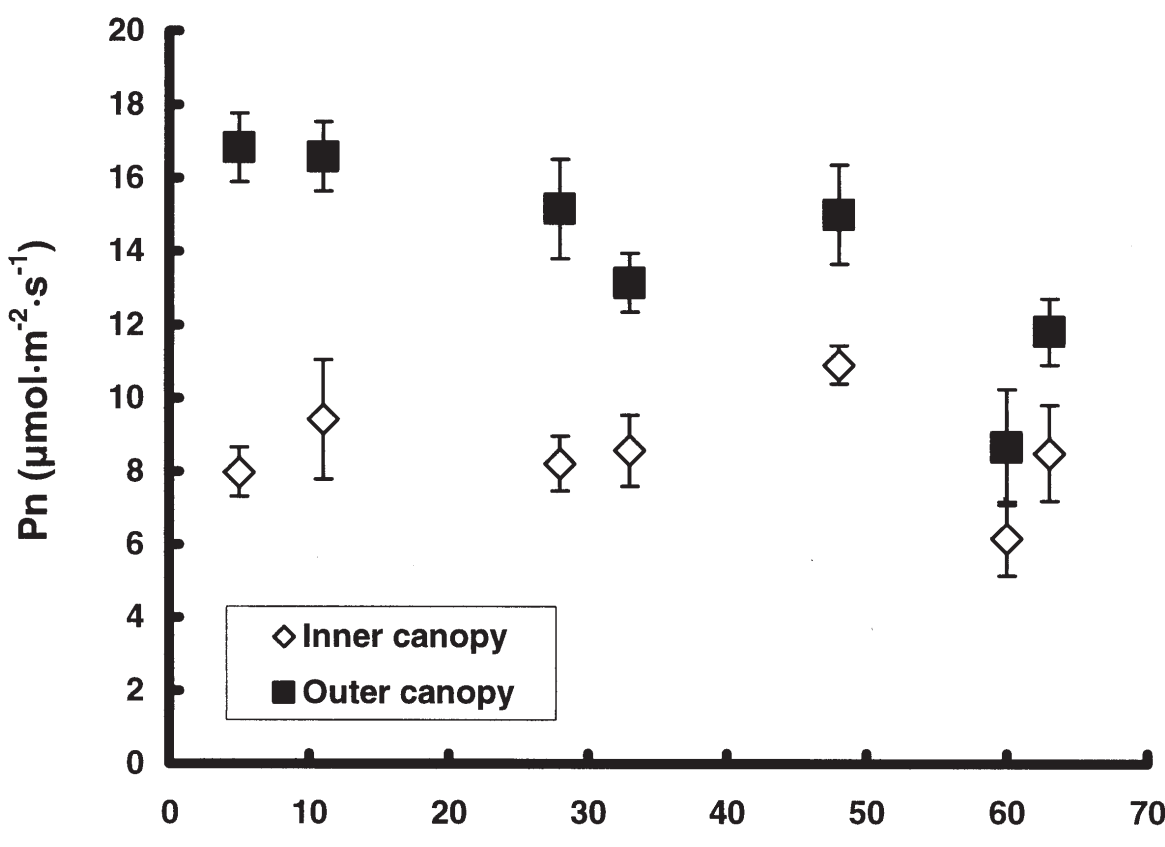

Days after summer pruning

Fig. 3. Seasonal trend of leaf Pn from interior and outer canopy on 14-year-old modified central leader 'Empire'/M.26 trees following summer pruning on 7 Aug. Values are means of three replicates of two leaves. Vertical bars represent standard errors.

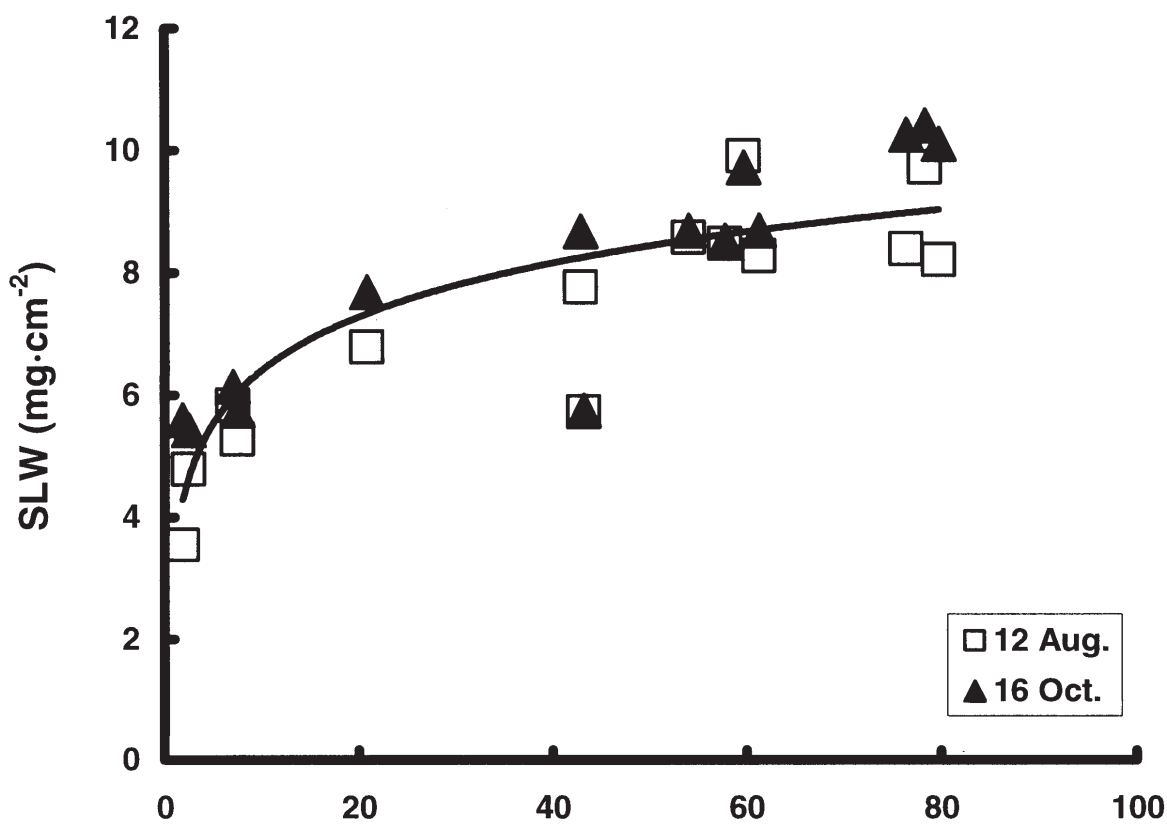

$\%$ total solar radiation availible before summer pruning

Fig. 4. Correlation between specific leaf weight (SLW) and pre-pruning light exposure on 14-year-old modified central leader 'Empire'/M.26 trees. Trees were summer pruned on 7 Aug. and harvested on 16 Oct. Cumulative solar radiation received from 5 June to 7 Aug. was $1340 \mathrm{MJ} \cdot \mathrm{m}^{-2}$. The regression model is $\mathrm{y}=1.25 \operatorname{Ln}(\mathrm{x})+3.5, r^{2}=0.7$.

pruning, and the vigor and the training system of the test trees.

Leaf photosynthesis response to pre-pruning light exposure. Light-saturated Pn just after pruning was low in leaves that had been most shaded before summer pruning (Fig. 2). Pn increased rapidly as previous light exposure
Although the interior canopy light environment was improved after summer pruning, there was no recovery of the photosynthesis ability of shade leaves (Fig. 3). Leaves in the inner and middle canopy sites had less than $75 \%$ photosynthetic efficiency of leaves in the outer canopy, and showed little evidence of recovery after re-exposure. The photosynthetic rate of leaves in the exterior canopy, especially of those exposed to the most sunlight, declined during September and October, possibly due to aging or the accumulation of environment stress (Marini and Barden, 1982b).

The Pn of the interior canopy leaves did not increase after pruning by thinning cuts in this study, as well as in other reports (Lakso et al., 1989; Porpiglia and Barden, 1981). However, Pn did increase after pruning by heading cuts in some earlier studies (Marini and Barden, 1982b; Myers and Ferree, 1983a; Taylor and Ferree, 1981). Marini and Barden (1982b) suggested several possibilities for the higher Pn rate after pruning treatment, including light adaptation, source-sink modification, and hormone-induced rejuvenation. Recently, Mierowska etal.(2002) found significant recovery of Pn capacity of spur leaves after exposure to high light intensity. As expected with normal summer pruning, the interior spurs in our study were partially, but not fully re-exposed to sunlight (Fig. 1). Therefore, the increase in light intensity experienced by these interior leaves may have been too small to induce recovery of Pn capacity.

Photosynthesis system II efficiency. The photosynthetic efficiency $\left(\mathrm{F}_{\mathrm{v}} / \mathrm{F}_{\mathrm{m}}\right)$ of interior leaves responded little to the increase in light exposure. The $\mathrm{F}_{\mathrm{v}} / \mathrm{F}_{\mathrm{m}}$ values varied only from 0.75 for most shaded leaves to $\approx 0.8$ for most exposed leaves. Greer et al. (1997) also showed no changes in $\mathrm{F}_{\mathrm{v}} / \mathrm{F}_{\mathrm{m}}$ through the growing season. In a recent study on shading effects in apple trees, Dolega et al. (1997) indicated that chlorophyll fluorescence and leaf Pn quickly responded to the application and removal of artificial shading. Unfortunately, they didn't mention which fluorescence parameter had been recorded.

Specific leaf weight, light, and photosynthesis. Shortly after summer pruning treatment, SLW and canopy light availability before pruning were related nonlinearly (Fig. 4). Barden (1974) and Barritt et al. (1987) also reported a positive relationship between these variables. The relationship between SLW and canopy light exposure in October was similar to that in August. The result is contrary to that reported by Barden (1974), who found that exposure to full sunlight significantly altered SLW even after the leaf was fully mature.

SLW has been proposed as a good index of the previous $P P F$ condition and Pn potential (Barden, 1978). We found a good linear correlation between SLW and Pn in Aug. (Fig. 5). However, non-uniform senescence of leaves can invalidate the index (Lakso and Lenz, 1986). The relationship became unclear after harvest in October.

\section{Conclusions} (1989), although they showed as continuous shade reduction. Our results support the general conclusion that post-pruning $\mathrm{Pn}$ is predetermined by prepruning light exposure. increased to $\approx 20 \%$, but Pn increased little for leaves previously exposed to $>20 \%$ light. A similar relationship was reported by Lakso et al. 


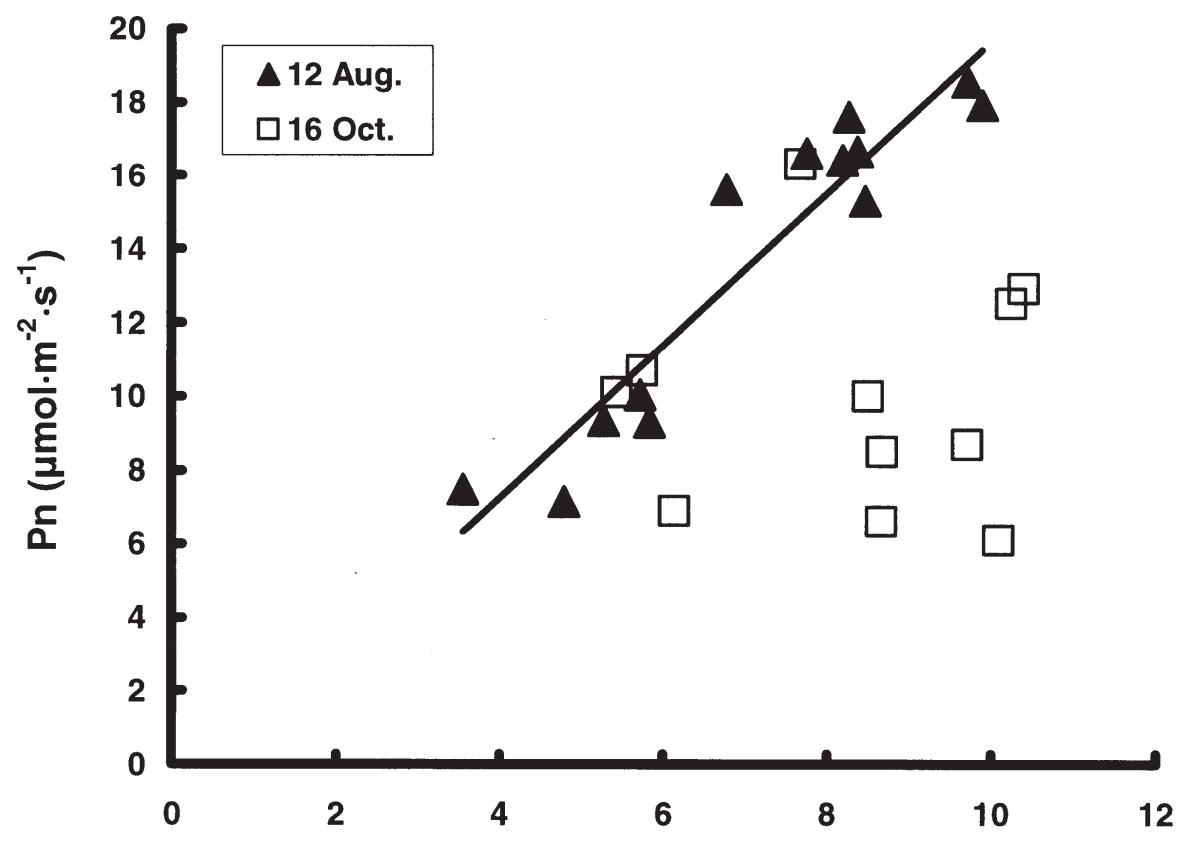

\section{$\operatorname{SLW}\left(\mathbf{m g} \cdot \mathrm{cm}^{-2}\right)$}

Fig. 5. Light-saturated leaf net photosynthesis (Pn) as a function of specific leaf weight (SLW) on 14-yearold modified central leader 'Empire'/M.26 trees summer pruned on 7 Aug. Leaves were sampled on 12 Aug. and 16 Oct. The regression model for measurements on Aug. is $\mathrm{y}=2.06 \mathrm{x}-1.01, r^{2}=0.89$.

leaves in the interior apple canopy to $<50 \%$ full sun. Previous canopy shade reduced the apparent photosynthetic ability of the interior leaves although the PSII efficiency did not appear to be affected. After re-exposure to higher light levels by summer pruning, the leaf photosynthetic ability did not significantly recover. Consequently, the reduction in average leaf photosynthesis that should result from removing exposed shoot leaves and re-exposing previous shaded spur leaves may play a role in the common observation of poor fruit sizing after summer pruning. Future studies need to quantify the effects of summer pruning on whole-canopy gas exchange, and the carbohydrate supply/demand balances that affect fruit development.

\section{Literature Cited}

Barden, J.A. 1974. Net photosynthesis, dark respiration, specific leaf weight and growth of young apple trees as influenced by light regime. J. Amer. Soc. Hort. Sci. 99:547-551.

Barden, J.A. 1978. Apple leaves, their morphology and photosynthetic potential. HortScience 13:644-646.

Barritt, B., C.R. Rom, K.R. Guelich, S.R. Drake, and M.A. Dilley. 1987. Canopy position and light effects on spur, leaf, and fruit characteristics of 'Delicious' apple. HortScience 22:402-405.

Boardman, N.K. 1977. Comparative photosynthesis of sun and shade plants. Ann. Rev. Plant Physiol. 28:355-377.

Dolega, E., W. Stadler, and L. Bertschinger. 1997. Junifruchtfallförderung durch Beschattung: interessante Versuchsresultate 1997. Obst- Weinbau 133:590-591.
Marini, R.P. and J.A. Barden. 1982c. Yield, fruit size, and quality of three apple cultivars as influenced by summer or dormant pruning. J. Amer. Soc. Hort. Sci. 107:474-479.

Marini, R.P. and J.A. Barden. 1987. Summer pruning of apple and peach trees. Hort. Rev. 9:351-375.

Mierowska, A., N. Keutgen, M. Huysamer, and V. Smith. 2002. Photosynthetic acclimation of apple spur leaves to summer-pruning. Sci. Hort. 92:9-27.

Mika, A. 1986. Treatments improving illumination of the fruit zone of the tree, p. 42-45. In: A.N. Lakso and F. Lenz (eds.). The regulation of photosynthesis in fruit Trees. Symp. Proc. Publ., N.Y. State Agr. Expt. Sta., Geneva.

Mika,A. and R. Antoszewski. 1972. Effect of leaf position and tree shape on the rate of photosynthesis in the apple tree. Photosynthetica 6:381-386.

Monteith, J.L. and M.H. Unsworth. 1990. Principles of environmental physics. 2nd ed. EdwardArnold, London.

Morgan, D.C., C.J. Stanley, R. Volz, and I.J. Warrington. 1984. Summer pruning of 'Gala' apple: The relationships between pruning time, radiation penetration, and fruit quality. J. Amer. Soc. Hort. Sci. 109:637-642.

Myers, S.C. and D.C. Ferree. 1983a. Influence of summer pruning and tree orientation on net photosynthesis, transpiration, shoot growth, and dry-weight distribution in young apple trees. J. Amer. Soc. Hort. Sci. 108:4-9.

Myers, S.C. and D.C. Ferree. 1983b. Influence of time of summer pruning and limb orientation on yield, fruit size, and quality of vigorous 'Delicious' apple trees. J. Amer. Soc. Hort. Sci. 108:630-633.

Palmer,J.W. 1989. Canopy manipulation for optimum utilization of light, p. 245-262. In: C.J. Wright (ed.). Manipulation of fruiting. Butterworths, London.

Palmer, J.W., D.J. Avery, and S.J. Wertheim. 1992. Effect of apple tree spacing and summer pruning on leaf area distribution and light interception. Sci. Hort. 52:303-312.

Porpiglia, P.J. and J.A. Barden. 1980. Seasonal trends in net photosynthetic potential, dark respiration, and specific leaf weight of apple leaves as affected by canopy position. J. Amer. Soc. Hort. Sci. 105:920-923.

Porpiglia, P.J. and J.A. Barden. 1981. Effects of pruning on penetration of photosynthetically active radiation and leaf physiology in apple trees. J. Amer. Soc. Hort. Sci. 106:752-754.

Robinson, T.L. 1997. Interaction of tree form and rootstock on light interception, yield and efficiency of 'Empire', 'Delicious' and 'Jonagold' apple trees trained to different systems. Acta Hort. 451:427-436.

Saure, M.C. 1987. Summer pruning effects in apple: A review. Sci. Hort. 30:253-282.

Taylor, B.H. and D.C. Ferree. 1981. The influence of summer pruning on photosynthesis, transpiration, leaf abscission, and dry weight accumulation of young apple trees. J. Amer. Soc. Hort. Sci. 106:389-393

Tustin, S., L. Corelli-Grappadelli, and G. Ravaglia. 1992. Effect of previous-season and current light environments on early-season spur development and assimilate translocation in 'Golden Delicious' apple. J. Hort. Sci. 67:351-360.

Wünsche, J.N., A.N. Lakso, T.L. Robinson, F. Lenz, and S.S. Denning. 1996. The bases of productivity in apple production systems: The role of light interception by different shoot types. J. Amer. Soc. Hort. Sci. 121:886-893. 